\title{
Article
}

\section{A review of the generic design assessment (GDA) dialogue pilot (2015) for new nuclear build in the UK: lessons for engagement theory and practice.}

\author{
Whitton, J, Parry, Ioan, Grundy, C, Lillycrop, A and Ross, D \\ Available at http://clok.uclan.ac.uk/14627/ \\ Whitton, J ORCID: 0000-0001-6391-5740, Parry, loan ORCID: 0000-0003-1847- \\ 3036, Grundy, C, Lillycrop, A and Ross, D (2016) A review of the generic \\ design assessment (GDA) dialogue pilot (2015) for new nuclear build in the \\ UK: lessons for engagement theory and practice. Journal of Radiological \\ Protection, 36 (2). ISSN 0952-4746
}

It is advisable to refer to the publisher's version if you intend to cite from the work. http://dx.doi.org/10.1088/0952-4746/36/2/S23

For more information about UCLan's research in this area go to http://www.uclan.ac.uk/researchgroups/ and search for < name of research Group>.

For information about Research generally at UCLan please go to http://www.uclan.ac.uk/research/

All outputs in CLoK are protected by Intellectual Property Rights law, including Copyright law. Copyright, IPR and Moral Rights for the works on this site are retained by the individual authors and/or other copyright owners. Terms and conditions for use of this material are defined in the policies page.

\section{CLoK}

Central Lancashire online Knowledge www.clok.uclan.ac.uk

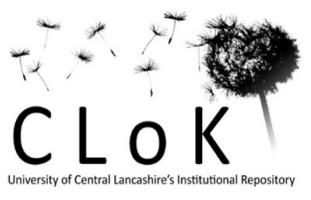


A review of the Generic Design Assessment (GDA) Public Dialogue Pilot (2015) for new nuclear build in the UK: lessons for engagement theory and practice

This content has been downloaded from IOPscience. Please scroll down to see the full text. 2016 J. Radiol. Prot. 36 S23

(http://iopscience.iop.org/0952-4746/36/2/S23)

View the table of contents for this issue, or go to the journal homepage for more

Download details:

IP Address: 193.61.255.86

This content was downloaded on 16/08/2016 at $14: 58$

Please note that terms and conditions apply. 


\title{
A review of the Generic Design Assessment (GDA) Public Dialogue Pilot (2015) for new nuclear build in the UK: lessons for engagement theory and practice
}

\author{
John Whitton ${ }^{1,5,6}$, Ioan Parry ${ }^{1,5}$, Colette Grundy ${ }^{2,5}$, \\ Annabelle Lillycrop ${ }^{3,5}$ and David Ross ${ }^{4,5,6}$ \\ ${ }^{1}$ Energy and Society Research Group, University of Central Lancashire, Preston, UK \\ 2 NNL Laboratory Fellow, National Nuclear Laboratory, Warrington, UK \\ ${ }^{3}$ Senior Stakeholder Engagement Adviser, Environment Agency, Bristol, UK \\ ${ }^{4}$ Senior Technology Manager (recently retired) National Nuclear Laboratory, \\ Warrington, UK
}

E-mail: jwhitton@uclan.ac.uk, imparry@uclan.ac.uk, colette.grundy@nnl.co.uk and annabelle.lillycrop@environment-agency.gov.uk

Received 30 September 2015, revised 16 March 2016

Accepted for publication 7 April 2016

Published 6 June 2016

\begin{abstract}
We have discussed previously that a community-based, asset-based approach is required to achieve any sense of how social sustainability can be defined in a community setting within the context of energy developments. Our approach aims to initiate a lasting change within 'energy' communities through building social capital; focusing on community assets not deficits to define their social priorities. Through deliberation, we develop an understanding of social sustainability so that a community is well placed to enter discussions with government and industry regarding large energy developments that will directly affect them.

We review the 2015 Generic Design Assessment (GDA) Public Dialogue Pilot process for potential new nuclear reactors in the UK. We examine the aims of the dialogue, giving particular attention to a comparison between the national sampling of citizens for the GDA and the local community-based, deliberative approach we have proposed previously. We find an ongoing tension between 'national' engagement processes (such as the GDA Public Dialogue Pilot process) and the specific requirements of those energy communities that live adjacent or close to energy infrastructure, manifested here by a conflict between the requirements of the convenor and those of participants regarding priority issues for discussion. We also reveal a paradox; despite participant
\end{abstract}

\footnotetext{
${ }^{5}$ These authors contributed equally to this work.

${ }^{6}$ Author to whom correspondence should be addressed. 
preference for a remote, internet-based engagement process, they agreed that face to face contact is a priority to encourage trust building between participants and the convenor of the process - a desired outcome of the process.

The GDA Public Dialogue Pilot process has demonstrated that stakeholders are willing to engage with and be more directly involved in local energyrelated decisions that affect them directly, provided there is opportunity to discuss locally-relevant and site-specific issues in addition to those of a broader nature. There exists a disparity and conflict between 'national' engagement processes and the 'local' priorities of those energy communities that are adjacent or close to energy infrastructure. In this process and others, we have seen an imbalance between the requirements of the convenor and those of participants regarding priority issues for discussion. This continues to be a persistent challenge for those convening stakeholder engagement events where the scope and context is not primarily site-specific. However, it is encouraging that convenors and participants alike continue to be willing to work towards resolving this.

Keywords: nuclear energy, engagement, Generic Design Assessment, communities, social sustainability

(Some figures may appear in colour only in the online journal)

\section{Introduction}

The decisions made regarding the management of both aging and new energy infrastructure are of local, national and international importance. Improved dialogue between industry and stakeholders can significantly impact upon the quality of decision-making [1] demonstrating a more democratic decision-making process, particularly at the local scale. We have previously proposed a systemic, community-led, asset-based approach to societal dialogue that captures the views and concerns of the stakeholder community; this also has the potential to inform public views, inform community and strategic levels of decision-making [2]. We have argued that this type of approach is critical in understanding how 'social sustainability' is conceptualised and envisioned within the context of energy developments. This is achieved by identifying social priorities, through deliberation with people living within communities impacted by large-scale, energy-related developments. Communities are then well placed to enter into discussions with government and industry regarding developments that will directly affect them.

The GDA process is a pre-licensing requirement for any nuclear reactor design proposed for the UK. It entails a number of steps, at which there is the opportunity for the public to comment. The GDA Public Dialogue process is a new pilot approach and study with the aim to provide information for the public through direct and deliberative dialogue. This paper discusses a pilot public dialogue process for the Advanced Boiling Water Reactor (ABWR) proposed by Hitachi-GE, which is proposed for development at proposed sites in South Gloucestershire, South West England and Anglesey, North Wales.

In this paper, we firstly discuss public engagement in the context of energy developments, the support for dialogue-based communication, and the involvement of stakeholders in energy-related decision-making processes. The authors also consider notions of justice and fairness in the context of engagement, specifically within a social context. In section 3, we present a brief history of the GDA process and associated events. We broadly define and 
describe GDA, followed by a discussion of the GDA Public Dialogue Pilot process, including aims, objectives and notable findings of the process. In section 4, we discuss these findings and process outcomes in the context of themes such as decision making, public engagement and social sustainability. We discuss the role of nuclear regulators within the dialogue and how this has evolved to address issues such as improving regulatory trust and ensuring fairness of process, and how this can contribute towards our notions of social sustainability. In the Conclusion we discuss the strengths and limitations of the GDA Public Dialogue Pilot process, what this means in the wider context of the UK planning and decision-making processes, and how successful the GDA Public Dialogue Pilot process reviewed here was in meeting its original aims and its potential impact for future processes. Finally, we discuss our conceptual framework for engaging communities and identifying social priorities for the purpose of informing decision-making processes for large-scale energy developments [2] and improving decision-making strategies, accompanied by a brief review of the relevant literature.

\section{Engagement for energy developments}

Political theorists and social scientists have traditionally argued that concepts related to public acceptance (e.g. fairness, justice) are of greatest importance regarding participation in policy setting, while those arguing from an economic and more traditional scientific perspective have argued that the quality of the decision and process is more important [3], and that technical decisions should be 'left in the hands of experts and scientists' ([3]: p. 5). As Rowe and Frewer [3] discuss with reference to the 'deficit model', some authors have historically argued that the inadequacies of laypeople, in terms of their abilities to reason, and their knowledge and understanding of complex information and concepts, limit their capacity to effectively contribute to technical or policy decision processes (e.g. [4-6]). However, in the process of EU environmental impact assessment for example, scientists and economists are required to engage in public consultation, which constitutes modern standard practice (see [7]).

The industrial (or 'grey') literature has for many years acknowledged the need for stakeholder engagement and that social considerations are made. In the highly scientific and technically-focussed field of radiation protection, it has been proposed by some that a solely scientific approach to assessment may be inappropriate, and that scientific assessment should reflect a combined operation incorporating expertise from different disciplines, including sociology [8]. There have also been a number of scientific initiatives where the involvement of lay people in technical and scientific policy processes has been promoted (e.g. [9, 10]); however, public participation in decision making is sometimes limited to informing decision-making processes as opposed to actively participating in them (e.g. [11]). On the topic of public dialogue on science and technology, it is highlighted in a report by UK-based organisation Sciencewise [12] that the scientific, political and public sector communities had for too long pursued a public engagement approach which relied too heavily upon scientific communication, and that an approach of listening and engaging in two-way communication, i.e. public dialogue, was more appropriate and further required.

Other academic authors highlight a general agreement in the nuclear field regarding the importance of involving the public in other nuclear-related processes, such as the geological disposal of radioactive waste [13]. Richardson et al [13] note the potential of increased public engagement to enhance nuclear safety and also improve relations between the nuclear industry and local stakeholders: 
"More engagement with the public in a formal process that accepts and respects the validity of scrutiny from civil society represents an immediate step the nuclear industry can take that provides additional oversight, builds confidence and can contribute to increased safety" [p. 267]

"An open process of integrating public involvement into operations can trigger a positive feedback cycle creating mutual trust between the operator and the stakeholder communities, and also reinforce and enhance the safety culture" [p. 271]

In a recent Nuclear Industry Council report [14], a focus on dialogue in the context of public engagement is promoted, which enables the identification of issues of public importance, and also for the industry to 'respond to these more effectively' (p. 5). Such recent publications indicate that the nuclear industry has made significant advances in the field of stakeholder engagement, and now acknowledge, in a move away from a reliance on scientific information provision and communication, that dialogue is a necessary component to effective engagement.

When discussing highly technical projects such as nuclear power developments, the argument for quality decisions based on the best technical data available is hardly surprising. However, the traditional and 'technocratic' approach to decision making, which has historically excluded the views and input of lay people, has sometimes failed in the past when decisions made have been subjected to public scrutiny. For example, Whitton $[15,16]$ worked with Nuclear Decommissioning Authority (NDA) stakeholders between 2007 and 2010 to understand individuals' perceptions of the type of dialogue used to engage them and their perceived influence on NDA decision-making. The findings from two questionnaires, followed by a sample of interviews, recorded that the ability of participants to express views, have fair engagement with NDA, understand other stakeholder positions and expect transparency regarding their influence was important to participants. Despite these being achieved in part, there remained confusion among many individuals regarding the extent of their influence on decision-making, their role in the process, and the nature of the dialogue being implemented. Whitton [15] suggests that much of this is due to a lack of what the literature terms reciprocity: transparency regarding how the views of stakeholders influence strategy and associated decision making.

In the UK, support for greater dialogue-based engagement from Central and Local Government, and Government agencies has increased in recent years, in order to encourage public involvement in decision-making processes to inform and influence a range of issues and policies [16]. Dryzek [17] highlights the 'deliberative turn' in democratic theory at the end of the twentieth century, in a move towards greater democratic legitimacy and involvement of those affected by collective decisions through dialogue and deliberation. Examples of 'successful' industry-stakeholder dialogue in the UK include the decommissioning of Trawsfynydd Nuclear Power Station [18]. This case study, where public participation contributed in selecting decommissioning options for the power station, is uncommon in that it demonstrates local community involvement in nuclear decision-making processes which was deemed 'successful'. Cotton and Devine-Wright [19] concur with such an observation of dialogue as an uncommon practice during energy developments in their study of public engagement in electricity transmission infrastructure planning in the UK. They observe that while network operators claim to support deliberative dialogue with the public, opportunities and evidence of such public engagement are lacking, with citizens perspectives remaining on the periphery of decision-making. Such involvement of local stakeholders has been suggested as vital to project management and development. Kemp, Bennett and White [20] describe various practices and techniques in stakeholder dialogue in the context of UK nuclear waste 
management, emphasising the importance of engaging fully with local stakeholder groups. Stakeholder dialogue has also been promoted as a critical component for renewable energy technologies, such as biomass technology developments in the Netherlands [21], as for any large development with significant environmental impacts:

“...in order to deal with complex environmental issues, structured stakeholder dialogues are needed that map out and articulate the various perspectives - values, interests, knowledge claims and underlying assumptions - that exist with regard to the issue" [p. 579].

Although the positive impact of greater participatory decision-making procedures on public acceptance has been documented for different large scale energy infrastructure [22, 23], dissatisfaction with a top-down, technocratic policy of energy decision-making has led to public 'acceptance' becoming a divisive and controversial term when applied to nuclear energy and radioactive waste management policies, such as in Japan for example [24]. Indeed, social movements in Japan are increasingly challenging the top-down, technocratic system of energy decision-making, calling for more dialogue with the public [2]. The importance of involving local professionals and communities which have been affected by the 2011 Fukushima Daiichi accident in local rehabilitation efforts is one recommendation among many made by the International Commission on Radiological Protection [25]. Such recommendations form part of the ICRP Fukushima Dialogue Initiative, which reflects a collaboration of the ICRP and Radiation Safety Forum Japan from late 2011, and which sought to 'transfer experience from communities effected by Chernobyl, facilitate discussions between stakeholders, and deeply understand the challenges in order to improve future ICRP recommendations' [25]. This in part reflects an acknowledgement of the value of local experience and dialogue with public stakeholders in addressing complex nuclear issues. The link between public trust and 'acceptance' has been recently highlighted in the energy literature; in a cross-national study on public acceptance of new high voltage power lines (HVPL), Aas et al [26] found significantly low levels of trust towards grid networks and operators, and consistently low levels of acceptance of HVPL developments, both locally and generally. The authors note that their findings and those of other energy-related empirical studies [27-31] demonstrate that local acceptance is commonly lower than general acceptance, thus highlighting the importance for local approaches to address issues of trust if developments are to gain public consent.

The option based on the pinnacle of technical excellence may not be acceptable to the wider public or appropriate in a community setting. This corresponds with notions of Post-Normal Science Theory (see [32-35]), arguing that the scientific system must move beyond the traditional 'reductionist' approach, which relies almost exclusively on industry or technical experts and is therefore deemed as insufficient, and that the role of the public and other stakeholders should be viewed as necessary if the scientific system is to be legitimate and democratic. As Funtowicz and Ravetz [32] argue, a post-normal science approach which promotes the collective production of knowledge, involving those 'affected by the issue who enter into dialogue on it' ([36]: p. 8), is appropriate when 'facts are uncertain, values in dispute, stakes high and decisions urgent' ([32]: p. 744, cited in [36]). Such participatory approaches are particularly relevant when decision-making on issues involving or presenting potential risks to society, such as energy infrastructure, in particular nuclear power developments, are considered. We argue that processes focussed towards gaining 'public acceptance' during nuclear decisionmaking should be avoided, so as to mitigate persistent perceptions of public coercion and persuasion. We suggest that through more inclusive and dialogue-based approaches, decisions will be more considerate of the legitimate, real-life concerns of impacted parties and potentially address public distrust in some nuclear officials participating in such 'acceptance-based' 
approaches, which have historically predominantly focussed on scientific 'truths' and have not sufficiently engaged with local concerns and priorities.

In a recent study, Batel and Devine Wright [31] promote gaining a deeper understanding of how groups and individuals in different places perceive particular developments. To do this, the authors suggest that a place-based, 'emplacement' perspective, as opposed to a siting perspective, should be taken to understand local perceptions of large-scale energy infrastructures. This emplacement perspective would focus upon how residents, both individuals and groups, within different settlements perceived and responded to specific energy infrastructures, 'referring not only to specific sites where developments are proposed, but also wider 'energy landscapes' that might be cumulatively affected by several low carbon infrastructure proposals' ([31]: p. 4; also see [36]). The authors also note the importance of understanding the characteristics of localities and the nature of the residents within these places to better understand response patterns to infrastructural developments, for example in regards to expected local impacts (see [37]). They state that their research highlights the possibility of 'more in-depth and context-sensitive information about people's beliefs regarding energy infrastructures' ([31]: p. 13) when examining individuals' responses based on 'communities of locality at the local level' [31]. In the next section we review the background to the GDA, followed by an outline of the process, specifically the GDA Public Dialogue Pilot.

\section{Generic design assessment (GDA)}

\subsection{Historical background to the GDA}

The UK Government's Energy Review in $2006^{7}$ considered the future role of new nuclear electricity generation. Following a public consultation in $2007^{8}$, the Government's Energy White Paper in 2008 proposed nuclear energy as a major contributor to the UK energy generating capacity. More recently, the National Policy Statement for Nuclear in July 2011 detailed planning and siting considerations for new nuclear infrastructure and reaffirmed this intention:

"The Government believes that energy companies should have the option of investing in new nuclear power stations. Any new nuclear power stations consented under the Planning Act 2008 will play a vitally important role in providing reliable electricity supplies and a secure and diverse energy mix as the UK makes the transition to a low carbon economy."

The Government identified a number of tasks that should be carried out to facilitate nuclear development, including a role for the UK Environment Agency (EA), Natural Resources Wales (NRW) and the Office for Nuclear Regulation (ONR) (the regulators) to develop a pre-licensing process for new nuclear reactors. The ONR is responsible for regulation of nuclear safety and security across the UK. The EA is the environmental regulator for the nuclear industry in England, whereas in Wales this role is undertaken by NRW. They are responsible for the regulation of radioactive discharges and radioactive waste disposals from nuclear power stations to ensure their impact to air, land and water is acceptable and minimised. The role of the regulators is to be independent and not to take a position for or against nuclear power. These regulators made submissions to the Department for Trade and Industry (DTI) following

\footnotetext{
${ }^{7}$ HM Government the energy challenge energy review report July 2006 www.gov.uk/government/uploads/system/ uploads/attachment_data/file/272376/6887.pdf

8 'Meeting the Energy Challenge: A White Paper on Energy' (May 2007), and 'Meeting the Energy Challenge: A White Paper on Nuclear Power' (January 2008).
} 
consultation with the nuclear industry on pre-licensing and pre-authorisation assessments for new nuclear power stations aimed at streamlining the regulatory process.

The aim of pre-licensing is to enable timely decisions to be made so new nuclear generating capacity can start to become available in time to replace existing stations. Other proposed benefits are to allow regulators to influence reactor designs at the design stage, potentially reducing cost and time impacts by avoiding modifications during construction. The submissions on the pre-licensing process proposed a two phase process, with one addressing generic design matters, named the Generic Design Assessment (GDA) and the other phase concerning site specific applications. It was suggested that the first pre-authorisation/licensing phase, GDA would be carried out by a joint regulatory project team involving the ONR and the EA. The process would include a detailed assessment of a candidate reactor design (or several designs) at the end of which the regulators would make a statement on its acceptability to be built in the UK and meet regulatory expectations. The GDA, including public consultation, would take 48 months to assess a reactor design.

In preparing its submission to DTI, the EA reviewed past experience of its predecessor body, Her Majesty's Inspectorate of Pollution (HMIP), in authorising new nuclear reactors ${ }^{9}$. The experience gained from Sizewell B, the most recent nuclear power station to be built in the UK, was reviewed in developing the pre-licensing process. Sizewell B, the UK's only civil pressurised water reactor (PWR) began generating in February 1995. It took over 14 years for the station to come into operation including 6 years associated with the initial planning inquiry and regulatory decision making, and the remainder for construction and commissioning. During the 6 year period of regulatory decision-making, a public enquiry was held which began in January 1983, and ended in March 1985, with an inquiry report published in January 1987. Applications for authorisations for radioactive waste disposals (including discharges to air and water and disposal off site) under the radioactive substances act 1993 (RSA 93), were finally made in 1993. However, as a result of a judicial review on an RSA 93 decision at another nuclear site it was necessary to extend HMIP's considerations to include Regulatory Justification. This made HMIP's considerations wider and its process longer, and could have prevented commissioning of the station at Sizewell.

Significant changes in the electricity supply industry have taken place since Sizewell B was proposed by the Central Electricity Generating Board (CEGB). Since the early 1990s, energy generation has been deregulated, new utility companies created and a competitive electricity market developed. The reactor supply industry has also changed significantly with more 'international' common reactor designs being offered by various reactor vendors. There are no UK specific reactor designs available, whereas all of the nuclear power stations built in the UK prior to Sizewell B, (i.e. Magnox and the Advanced Gas-cooled Reactors (AGRs) such as Hunterston and Torness in southern Scotland), were designed by the UK CEGB.

\subsection{Generic design assessment (GDA) process}

GDA began in August 2007 with the assessment of four reactor designs: AECL's ACR 1000, EDFAREVA's UK EPR, GE Hitachi's ESBWR and Westinghouse's AP1000. ONR adopted a four step process; in the first step, the design and safety case was reviewed at a high level and in Step 2 there was a fundamental safety review of claims made. Step 3 followed with a review of arguments in the overall design safety review, with Step 4 involving a review of evidence to support the detailed design assessment. The four steps in the ONR process involve increasing levels of scrutiny as does

\footnotetext{
${ }^{9}$ The Environment Agency's submission to DTI - Pre-licensing assessments of new nuclear power stations and streamlining the regulatory process (July 2006)
} 
the EA assessment process. The EA assessment ran in parallel to ONR's assessment, with an initiation step followed by a preliminary and then a detailed assessment. Public consultation followed (section 3.3), proceeded by the consideration of the consultation responses received, prior to the preparation of a decision document setting out whether a statement of design acceptability should be published. The final stage of the GDA process is the development of a statement of design acceptability representing the completion of the planned assessments by the regulators and identifying at that time the issues still to be resolved by the requesting parties to the satisfaction of the regulators.

Face-to-face meetings between the reactor vendors and potential operators with the regulators were used to explain technical approaches and support the understanding of regulator expectations for reactor vendors during GDA. The non-prescriptive nature of the UK Regulatory Framework and interpreting regulatory expectations was one of the significant challenges for reactor vendors in the first GDA process that began in 2007.

While GDA started in the UK in 2007, it was delayed from its original programme as a result of resourcing issues in the early stage, and the Fukushima accident in Japan. A review commenced in March 2011 to examine the circumstances of the Fukushima accident to see what lessons could be learnt to enhance the safety of the UK nuclear industry. Following interim statements, final statements of design acceptability were issued to AREVA/EDF for the EPR in 2012, valid for a period of 10 years. Westinghouse, who submitted the AP1000 reactor design, paused the GDA process with a number of GDA issues remaining. At the end of the first GDA, 31 issues remained for the EPR and 51 for the AP1000. Westinghouse have since recommenced GDA, and a new candidate reactor design, the UK ABWR is also undergoing GDA. AECL withdrew from GDA in 2008 and the ESBWR was also withdrawn shortly afterwards. Most recently, the Rosatom State Atomic Energy Corporation, a state corporation in Russia, announced that they intended to submit the VVER TOI design to the UK GDA process in 2015, however at the time of writing (early 2016) they are yet to do so. The Chinese CGN Hualong One design is also planned for submission to the GDA process in 2016, a reactor design proposed for the UK site of Bradwell, Essex.

\subsection{Public Dialogue Pilot process for the ABWR}

Public consultation has long been acknowledged as a necessary component to policy-related decision-making in Europe. For many years, the European Commission has advocated public participation, arguing that the transparency and accountability of the decision-making process is enhanced by public involvement [38]. An example of this at the European level is public participation in decision-making for environmental matters. The Aarhus 'Convention on Access to Information, Public Participation and Access to Justice in Environmental Matters', more commonly known as the 'Aarhus Convention' [39], was signed by the European community, including the UK, at the end of last century, and have since been required to adjust EU law to comply with its three 'pillars' of principles [40], which promote greater access and participation for the public:

- An 'access to environmental information' pillar: the public should be provided with wider and easier access to environmental information;

- An 'access to justice in environmental matters' pillar: the right of the public to recourse to administrative or judicial procedures to dispute acts and omissions violating the provisions of environmental law;

- A 'public participation' pillar: effective public participation in decision-making 'enables the public to express opinions and concerns relevant to those decisions, and for the decision-maker to take account of them. 
A period of public consultation is considered by the United Kingdom (UK) Government to be the correct process in which to involve the public in the development of new policy and legislation [41]. The feedback received from the consultation informs the Government's decision making process, resulting perhaps in policy or legislative changes. When new plans are large-scale and considered controversial, a planning inquiry (with independent adjudication) is often the route taken to derive an outcome. As the UK Government has a majority stake in the nuclear industry, this consultative process and associated guidance has been adopted; however, there are examples where the industry has gone further than consultation $[15,16]$.

An objective of the nuclear regulators' assessment of new nuclear power station designs is openness and transparency. The regulators are keen to build public confidence so have included engagement as part of the GDA process. An example of this is the regulators' consultation on their preliminary findings. The EA commissioned an independent evaluation of its GDA consultation in 2010 (see [42]). The findings from this evaluation suggested that the EA could seek to further improve its engagement with members of the public. The need to get better at presenting scientific and technical issues to the public so they can participate was the most common single suggestion for improving future consultations. To help address these findings in a systematic way, the nuclear regulators decided to undertake a public dialogue pilot. The regulators wanted to gain new perspectives and insights from members of the public so that their engagement and consultation can better meet peoples' needs. They also hoped to further build public trust in the regulators and their decisions, as part of the dialogue process.

The Public Dialogue Pilot asked three questions:

- How do members of the public want to be involved in the GDA process?

- What do people need to know (what are their concerns/interests?) and how can the nuclear regulators address their concerns/interests as part of the GDA process?

- What can the nuclear regulators do to help improve people's trust and confidence in their decisions?

The project outputs will help inform the EA and NRW's approach to consulting (due later in 2016) members of the public on their assessment of Hitachi-GE's UK Advanced Boiling Water Reactor (UK ABWR). Horizon Nuclear Power proposes to build this design on Anglesey in North Wales and at Oldbury in South Gloucestershire.

The objectives of the Public Dialogue Pilot Project were:

1. Identify approaches that will address issues and barriers to sharing complex technical information on the GDA with members of the public.

2. Inform the nuclear regulators' current and future public engagement, and EA and NRW's consultation approach on GDA.

3. Develop and pilot materials on the GDA that are accessible to the public.

4. Identify potential public engagement process options for the GDA.

5. Help the nuclear regulators to pilot an effective public engagement and EA and NRW consultation approach, during the current assessment of Hitachi-GE's UK ABWR.

3.3.1. Public Dialogue Pilot methodology. The Public Dialogue Pilot process was composed of three main stages. The first stage, which took place towards the end of 2014, involved an online national scoping survey of 401 people in England and Wales. This was carried out using online surveying software, and respondents were recruited from an online panel sample, which was formed from a variety of sources including online advertising, social media and 
targeted online recruiting in order to increase the numbers of specific demographic groups. This online scoping survey helped to inform the design of two subsequent workshops with members of the public by building a picture of national attitudes to the regulation of new nuclear power and the assessment of new reactor designs. Participants were asked 13 questions on a number of subjects, including:

- Knowledge of proposed nuclear developments and nuclear power station regulation in the UK.

- Trust in nuclear regulators in the UK.

- Public opportunities to find out information and ask questions about UK reactor design assessment process.

- Nuclear reactor assessment topics public would be interested in knowing more about.

- Preferred method of involvement in UK reactor assessment process.

Following the national scoping survey, the second stage involved two dialogue workshops (named 'Round 1 workshops' by the convenor). These were attended by a total of 41 people and were held in neutral meeting locations in the localities of the Oldbury and Wylfa sites proposed by Horizon Nuclear Power for the UK ABWR design-in Cheltenham (17th January 2015, held in a hotel conference room) and Bangor (31st January 2015, held in an event centre). These workshops were designed to provide an introduction to the topic and context of GDA, including the role of the regulators. During these Round 1 workshops, baselining questions were utilised to enable shifts in attitudes to be identified and recorded, regarding subjects such as their knowledge of nuclear power stations and how they are regulated, and their knowledge of and level of trust in the regulators (EA, ONR and NRW) at the beginning and end of each workshop. Participants would plot their 'position' on wall-mounted question grids to reflect their answers to questions at the beginning of the workshop, which was then repeated at the end of the workshop, thus attempting to demonstrate shifts in participant opinion throughout the day.

The third stage of the process involved a third workshop (named as the 'Round 2 workshop') with a mix of 18 participants from the earlier two sessions allowed a deeper exploration of key issues of interest which were raised but not answered fully in second stage workshops. These included nuclear waste (how much waste is produced and where does it go?), safety/ health issues of nearby people and long term impact on the environment, water disposal, long term impacts (what impact does this have in the future over 50-500 years?), and security (how much to tell the public and where to draw the line?) [43]. Also, a range of communication and consultation materials were reviewed and discussed to check they were accessible to members of the public. This workshop took place on 21st March 2015 in Crewe. The following section presents and discusses some of the findings from this process.

\subsection{GDA public dialogue pilot: findings}

At each stage of the process, there were several findings relating to public perceptions, preferences and opinions towards the topics covered, including a number of practical findings relating to engagement practices. We have used the findings of a study produced the company employed by the GDA process convenors [43] and have grouped the findings into three main themes: participation, dialogue and communication, and priorities.

3.4.1. Participation. In the following section, we discuss the findings relating to different aspects of participation, in particular who and how local stakeholders prefer to participate. The 
first stage of the process - the national scoping survey-aimed to provide a public response to questions on a range of subjects relating to 'nuclear power'. These included the importance that people attributed to participation activities, recording their geographical distances from a proposed nuclear site; these are referred to as those 'who to engage'. Overall, the national scoping survey found that it was those living closest to the site that were perceived as most important with which to engage; $79 \%$ of respondents felt that it was very important and $11 \%$ felt it was quite important that people who live within 25 miles of a proposed site have the opportunity to find out information and ask questions. Regarding those living over 25 miles from a proposed site, $44 \%$ of respondents stated it was very important, with $43 \%$ feeling it was quite important. For people outside England and Wales, $47 \%$ felt it was quite or very important that these people could find out information and ask questions [43].

As part of the national scoping survey, respondents also specified the processes through which they would prefer to participate, and were able to make more than one selection; these are referred to as 'how to engage'. $47 \%$ of respondents opted to participate via a website that explains the GDA assessment process. $28 \%$ stated that receiving a quarterly newsletter was most important, $26 \%$ preferred to respond to an online consultation, $17 \%$ would like to attend meetings to hear more and ask questions whilst $9 \%$ stated they would respond to a written consultation. $25 \%$ selected no further involvement. The Round 1 workshops highlighted that personal interaction and face-to-face contact is a significant factor in facilitating trust. Baselining questions utilised in these workshops enabled shifts in attitudes to be identified and recorded, as workshop attendees plotted their levels of trust of the regulators (EA, ONR and NRW) at the beginning and end of each workshop. A comment was made by one participant in the Bangor workshop reflecting the importance of personal interaction for building trust, stating that 'you can't trust anyone without a face' ([43]: p. 19).

Attendees from both Bangor and Cheltenham sessions convened for a Round 2 workshop in Crewe in March 2015. As a result of the workshop, it was possible to identify common themes and responses from attendees as to how they would prefer to engage and be engaged in future processes. Common themes identified were the use of local resources to improve and assist engagement with local stakeholders - that local enthusiasm and resources should be 'tapped into', by utilising those people who are engaged to encourage others to get involved. This included the targeting of local interest groups with interested members, particularly those groups who were represented at the workshop. Other related suggestions included utilising local publications and social media channels, and involving more young people, such as through a school project. Relating to the suggestion of engaging different social groups (see section 4.4), it was also proposed that the participation of different audiences or demographics would be more effective if different platforms and engagement methods were utilised.

In summary, workshop participants stated that the most important individuals to engage are those who live less than 25 miles from a proposed nuclear site. It was suggested by participants that personal interaction with these people will not only enable effective communication but will also facilitate the building of trust, and that a website explaining the GDA assessment process would also be preferable to local stakeholders. We conclude that this indicates a preference among participants for in-person local issue-related communication, where there is a greater likelihood for participants to ask questions of a sensitive nature of and seek clarification from experts, and for web-based national process-related communication, where the context may be less sensitive and participant questions may be less pressing. Among those living within a 25 mile radius of a proposed nuclear site, it was also suggested that local interest groups should be engaged, and that these groups, including young people, may then engage with other local stakeholders and encourage others to get involved, effectively utilising local human resources. We discuss types of approach further in section 4.4. 
3.4.2. Dialogue and communication. In the previous section, we presented findings related to the theme of participation; in this section we discuss dialogue and communication. We continue to discuss themes relating to public preferences on 'how to engage'. The GDA Public Dialogue Pilot process was facilitated through a dialogue between workshop attendees and facilitators. This is reflective of dialogue as proposed by Innes and Booher [44] - the multi-directional communication exchange between those participating in and facilitating workshops - which is valuable if engagement practice is to be effective (we discuss this further in section 4.4). Such notions are echoed in the industrial literature, such as the SAFEGROUNDS learning network program (e.g. [11]), where it is stated that two-way dialogue between 'experts' and the 'community' is important for 'open and straightforward communication' and that 'there should be a genuine willingness to take a different course of action if new information or insights are provided' ([11]: p. 24). We have already discussed how, from the findings of the national scoping survey, personal interaction is important for building trust and that communication tools such as a website explaining the assessment process is also desired by public stakeholders, as well as quarterly newsletters, and online consultations. Some opt out of the process altogether. Such findings demonstrate the diversity of preferences among local stakeholders in the context of engagement and communication, reflecting the social diversity found within local communities; in short, one size will not fit all, and a mix of communicative approaches is required in order to reach and communicate with various stakeholder groups.

'Context' was also identified as important in Round 1 workshops - any communication with local stakeholders should appreciate the individuality of communities and site-specific circumstances. Overall, participants stated a desire for broader and deeper information than was allowed by the scope of the GDA-related dialogue. Participants also preferred to speak about site-specific scenarios which reflected their personal and local context, rather than the generic approach and context which formed the basis for workshop dialogues. This highlighted the importance of 'relevance' in such communications with 'local residents'. During the dialogue, it was highlighted that many existing materials relating to GDA, which were presented to participants for their comment and feedback, were considered dense, technical and unengaging to participants. It was recommended that communication materials should be developed to be more engaging, with a particular focus on design, style, and visual imagery, and that these preferences will differ depending on the audience [43]. Such findings have wider implications for public-facing engagement and communication materials, particularly for communicating technical or complex subject matter. The broad message here is one which is relevant to a plethora of public and stakeholder engagement scenarios in the context of communication-rather than employing a broad-brush approach, ensure that the message is pitched appropriately to the audience.

During the Round 2 workshop, common messages emerged that are relevant to themes of dialogue and communication. These include ensuring communication is delivered to an appropriate level of complexity, which for most public stakeholders being engaged on technical subjects, means 'keeping it simple'. The use of examples that people were familiar with worked well during workshop presentations, demonstrating that every day analogies that people can relate to should be utilised where possible. It was also suggested that utilising simple ideas and concepts can assist in engaging with and involving younger and older audiences in particular [43]. The use of simple ideas communicated, where possible or appropriate, in a humorous and interactive way was suggested as critical in communicating technical or complex subjects in an engaging way which retains the attention and interest of the audience. Ensuring that an awareness of historical and local context and potential preconceptions is established prior to communication was highlighted as important when discussing issues or subjects with 
controversial or negative historical connotations; in these circumstances, it was suggested that previous incidents or failings are not avoided but presented, discussed, and then that the modern efforts to address these are also discussed [43]. Finally, ensuring that communication is made both personal, personable and understandable were also raised as critical factors contributing towards its effectiveness; communicating to people why the subject is of importance and relevance to them, in an objective, open, and engaging way, whilst ensuring that the message and language is at the appropriate level of complexity for the audience.

3.4.3. Prioritisation of stakeholder issues. The third theme in this section highlights public preferences or priorities for engagement. In the national scoping survey, a significant proportion of survey participants required more information on nuclear safety (82\%); radioactive waste management (78\%); the impact of radioactive discharges on people and the environment (76\%); nuclear security (64\%); spent fuel management (59\%); and 'other environmental impacts' $(50 \%)$ [43]. During the Round 1 workshops, whilst there were several questions relating to the topic of GDA, there were also a significant number of questions deemed 'outside the scope' of the workshop, but which served to highlight participant concerns and priorities prior to any engagement influence. These included energy policy; environmental and health impacts of nuclear power; power station design; nuclear waste and decommissioning; and local community impacts. In the Bangor workshop, social issues such as the impact on jobs and local employment relating to the proposed Wylfa Newydd nuclear power station on Anglesey were of particular concern. This highlights the potential of such processes to identify specific issues which, whilst being outside 'the scope' of the process reflect the priorities of public and local stakeholders. We discuss this approach further in section 4.4.

\section{Discussion}

\subsection{Public participation}

Historically, the relationship between the UK government-owned nuclear industry and its stakeholders can be summarised as starting from a position of what Elam and Sundqvist [45] have described as a 'technocratic strategy'. They define technocracy as 'the government control of society by an elite of technical experts' ([45]: p. 6). The technocratic approach-also known as decide-announce-defend (DAD)—was until relatively recently the norm in the UK, focussing on technical risk assessments rather than public engagement. In recent years, dialogue-based engagement has been promoted by an agenda in Central and Local Government, and Government Agencies, to encourage public involvement in environmental and general decision-making processes to inform wide ranging policy and strategy [16]. Flueler [46] records how the general need to involve stakeholders in the decision-making for radioactive waste management was highlighted at the International Atomic Energy Association (IAEA) conference in Cardoba in 2001, where a proposal was put forward to establish a broad international stakeholder forum. The proposal was tabled because in almost all the conference technical sessions there was discussion regarding the need to involve stakeholders in the decision-making process related to radioactive waste management. The author summarises that this was typical of discussion going on elsewhere within the industry at this time and represented a political and socio-economic change.

The discussion regarding the UK nuclear legacy needed to be radically re-framed to satisfy stakeholder concerns regarding legitimacy of any organization taking major decisions on the future decommissioning and disposal of the UK nuclear legacy. Reflecting on this, Kos, Polic and Železnik [47] state: 
"The side effect of these developments was a slow and reluctant transition from a technocratic decision-making model to a participatory decision making model. The recognition that perhaps the only chance to find a legitimate solution is the establishment of a complementary socio-technical decision-making model starts to gain ground" [p. 6].

A substantial literature supports the notion that greater public participation in decisionmaking serves to significantly reduce conflict, leading to more robust decisions for large energy infrastructure developments. Less opportunity for public participation increases the likelihood of public opposition and delays to developments [48]. Such developments include nuclear waste repository siting [49], electricity transmission and infrastructure planning [19, 50], wind energy developments [51], small hydropower projects [52] and rural renewable energy implementation [53]. The advantages of greater public participation are well documented, such as the participatory process adopted for nuclear waste management decisions in Sweden [54]. However, failure to sufficiently consider and involve the public can have negative consequences for similar projects, as has been the case in the Czech Republic [55], and in the UK [56], where a lack of trust has been shown to be a key factor in public uncertainty towards plans for a national nuclear waste repository. In reference to the GDA Public Dialogue Pilot process findings (see [43]), we have reported how those living close to nuclear sites (within $25 \mathrm{~m}$ ) are considered the most important of those citizens with whom to engage. The findings also highlight how despite a strong preference for web-based engagement, face-to-face contact is crucial for trust-building between stakeholders and process convenors. We conclude that face-to-face dialogue between process convenors and local stakeholders is important both for building trust and for mitigating negative consequences, such as local opposition and conflict, with the proposed developments.

Within the European context, the role and importance of stakeholder participation has been highlighted by Collins and Ison [57], as set out in the Aarhus Convention [39] and the Water Framework Directive [58]. This involvement is seen by the authors as an attempt to address the general decline in trust of decision-makers and the increasing 'democratic deficit' as promotional factors for greater participation. The lack of legislative drivers to encourage participation have been highlighted by Lee and Abbot [59], but the authors recognize that within Central Government there is a shift is taking place to address such democratic and constitutional perspectives. The impetus of government to reach those who are less than enthused by the political and democratic process in the UK has been stimulated by a decline in memberships to the main political parties combined with low electoral turnout; this issue is particularly evident for the most disadvantaged citizens [16]. In recent years, membership of 'other' political parties in the UK, such as the Green Party and Scottish National Party has increased significantly. However, public identification with a single political party has declined over recent decades, particularly among young people [60], reflecting a growth in political pluralism.

We have discussed previously in this paper how participants highlighted the role of 'capacity building' - that is using existing resources or training local residents to support and encourage participation in engagement activities. In a nuclear context, an example of efforts to implement capacity building can be seen in the US Department of Energy remediation program for former nuclear test sites in the Marshall Islands. The aim of the program is 'to engage local atoll communities in developing shared responsibilities for implementing radiation surveillance monitoring programs for resettled and resettling populations in the northern Marshall Islands' [61], with numerous radiation surveillance facilities being operated and maintained by Marshallese technicians. The authors argue that the role of capacity 
building, particularly when it is suggested or requested by local stakeholders, can be a facilitative factor in more effective stakeholder engagement, trust-building and development support at the local level, and thus should be incorporated more widely at both nuclear energy and legacy sites.

Similar effects have been found in regards to other large-scale energy infrastructure in Europe. Aas et al [26], believed to be the first cross-national comparative study into public acceptance of new high voltage power lines (HVPL), suggest that there are common public perceptions in the UK, Norway and Sweden of weak local resident involvement in planning and decision-making processes, the implied impacts of which, on trust and local acceptance in particular, have been noted earlier in this paper.

As Miller et al [62] assert, energy policy institutions have operated out of the public eye and with minimal public involvement for many decades. However, they now face new challenges as the public becomes more knowledgeable of, attentive, and responsive to energy choices. Transitions in socio-energy systems, particularly concerning large-scale energy infrastructure and contentious technologies such as nuclear power, produce wide ranging social impacts and result in power reconfigurations across communities. These have led to widespread social protest and conflict surrounding energy policy decisions (ibid), realities which further support a shift to an approach to local decision-making, as we propose, promoting greater aspects of procedural justice (see [2]).

\subsection{Dialogue and communication}

Although we promote public participation as a critical element of decision-making, we acknowledge that challenges and limitations exist with participatory approaches. As Whitton et al [2] discuss, these can include a dearth of peoples' interest or time to participate; an inability to engage with, discuss or debate highly technical issues or concepts to an appropriate or sufficient degree; potentially significant costs associated with organizing and conducting workshops or public engagement sessions; consultation fatigue; and causing public mistrust if the process is seen to be merely a 'box-ticking exercise' for a pre-determined decision, with no genuine opportunities to influence outcomes or decision-making [36, 37, 63]. These being considered, we have suggested previously that new approaches to engagement are necessary if public consent for development is truly sought by government and other decision-makers [2]. The role of 'context', specifically the desire for broader and deeper information than was available through the GDA Public Dialogue Pilot process has been highlighted in our study. Many nuclear sites in the UK have a long and complex history, where there is a strong sense of ownership felt by the local community [16].

Participants in the GDA Public Dialogue Pilot process highlighted the relatively narrow 'generic' scope of the dialogue as a concern. Amendments to UK planning and infrastructural law detailed within the 2014-2015 Infrastructure Bill suggest that the new legislation will depart from that which it proceeds, namely the Planning Act (2008) and the Localism Act (2011), which aimed to involve local communities in decisions which affect them. The Infrastructure Bill under review appears to suggest more decision-making powers being transferred to the Secretary of State, enabling the mitigation of 'barriers and delays' for large-scale developments, particularly in the low-carbon energy sector, that we suggest, in a retreat from the deliberative turn observed by Dryzek [17], may indicate the beginning of a 'deliberative U-turn' in UK infrastructural politics. Whilst processes such as the GDA for new nuclear reactor designs proposed for the UK seem to provide a process with national and local scope and 
implications which seeks to continue along the deliberative path, the opportunity for public influence in decisions remains limited.

\subsection{Stakeholder prioritisation}

The decisions made regarding the management of new and aging energy infrastructure are of local, national and international importance. Improved dialogue between industry and stakeholders can significantly impact upon the quality of decision-making [64], demonstrating a more democratic decision-making process. The literature supports democracy, in governance and society, to be a key theme of social sustainability [65], which we discuss in section 4.4. In our previous work [2], we evidence the shift in the nature of the energy stakeholderindustry relationship through reference to our work at UK nuclear sites $[15,66]$, where there has been an increase in dialogue taking place but questions regarding the fairness of this dialogue for stakeholders. What is clear from both our previous and current work is that participants identify issues they see as a priority for discussion, but that are outside of what the convenors consider to be the scope. This seems to go against an ideal of fairness that we first referred to in section 2 of this paper. The definition of fairness we have used previously by Beierle ([67]: p. 740) refers to the 'broad representation and equalization of participant's power'. Stakeholders are unlikely to remain involved in a process where they continue not to be heard.

However, in democracies, obtaining public consent for development of any kind is challenging. We have demonstrated this by reference to our previous research at US nuclear sites, where open competition for consent for energy-related developments appears to improve the quality of the scientific choices made and the stability of these choices with a public faced by adverse events [68]. We embrace the move towards a participatory-based form of dialogue in decisions rather than a technocratic 'top-down', expert-led, 'one-way' form of consultation like that we discussed with reference to our research in Japan [2]. In our social sustainability framework that we discuss in the next section, dialogue is multi-directional and dimensional [44]. The findings from the GDA Public Dialogue Pilot process highlight the potential of such processes to identify specific issues which, whilst being outside 'the scope' of the process reflect the priorities of public and local stakeholders.

In the next section we offer an alternative framework; one that aims to promote a dialogue based on those issues that stakeholders identify as priorities. The importance of and need for further research into understanding the perceptions, priorities, involvement and support of local residents regarding large scale energy infrastructure is evident, and Walker, Wiersma and Bailey [65] echo this in the following statement:

"How to ensure fair processes and just outcomes for local communities, and how to enhance the acceptability of energy generation facilities amongst local populations remain important areas of human-energy research." [p. 46]

\subsection{Social sustainability}

We have previously presented a conceptual framework [2] to derive a systemic view of community-led priorities - that is, the social construction of affected communities. In our framework, dialogue is not only 'two-way', but multi-directional, dimensional, and incorporative of multiple stakeholders [44].Through the application of our framework, we aim to start to 
provide the tools required for communities to effectively engage and influence Government and Industry on decision-making that directly impacts upon them. The conceptual framework proposed is based on the assumption that a diverse range of social priorities is held by various stakeholder and social groups and that this is representative of the wider community; this has proved to be the case for the GDA dialogue. We have asserted previously that considering 'the public' as a single, uniform entity is unhelpful in regards to effective engagement [2]. As Pidgeon [69] states, there are a wide range of views in 'nuclear communities' which represent a 'diverse set of publics' (p. 2). We have suggested that by understanding this range of priorities, and developing 'priority profiles' for different social groupings, more informed, legitimate and sustainable decisions can be made within communities [2]. In consideration of sustainable decision-making for new energy projects, the conceptual framework is informed by the work of Raven et al [70, 71]. For goals of social acceptance for new energy projects, the value of incorporating the views and contributions of local stakeholders should not be underestimated, as they can assist decision-makers in anticipating and avoiding potential problems with societal acceptance. The authors' ESTEEM model employs vision building techniques and identifies conflicting issues with stakeholders. By doing so, later conflict may be avoided, as projects are able to develop more sustainably by incorporating a detailed understanding of stakeholder expectations and priorities, and formulating more socially acceptable options and solutions.

The framework presented in figure 1 is informed by our previous work [2], but also reflects the emphasis on two-way dialogue and understanding local priorities. As discussed, this is promoted in both the academic and industrial literature, sharing similarities with recent recommendations from sources such as the NIC [14] and Safegrounds [11]. Our framework includes a series of dialogue-based workshops with different stakeholder/social groups, to identify their social priorities and deliberate these in the context of a nuclear power development-or any other large-scale development. By working through sustainability criteria we then reach priority areas for consideration for during institutional and governmental decisionmaking processes, considering necessary factors that would attain 'social sustainability' for communities living close to energy developments. The conceptual framework also proposes the utilisation of community visioning and 'backcasting' techniques with stakeholders, in order to envisage 'desirable future' scenarios and what steps would be necessary in order to arrive at these futures, establishing sustainability pathways working backwards from these future scenarios to the present day (see figure 1). Structurally, the communityled conceptual framework for social sustainability operates on two levels. The first allows communities to define their priorities and understand how social sustainability may be constructed, as either as a social group or as a community collective of individuals. The second is to produce clear views from the community to inform institutional and governmental decision-makers.

By identifying community priorities, we not only establish what is important to local stakeholders who are or will potentially be impacted by existing or proposed developments, but also what we term 'likely areas of social impact' (LASI). Communities and decision-makers can then work to improve decision-making strategies to mitigate such impacts. This has the opportunity to mitigate negative impacts not only for communities, but also for decisionmakers and developers who can be severely impacted by conflict and project delays. This is particularly relevant for technologies such as nuclear power, which is categorised by Cotton [72], among other technologies such as hydraulic fracturing for shale gas, under the term 'socially and ethically contentious technologies' (SECTs). 


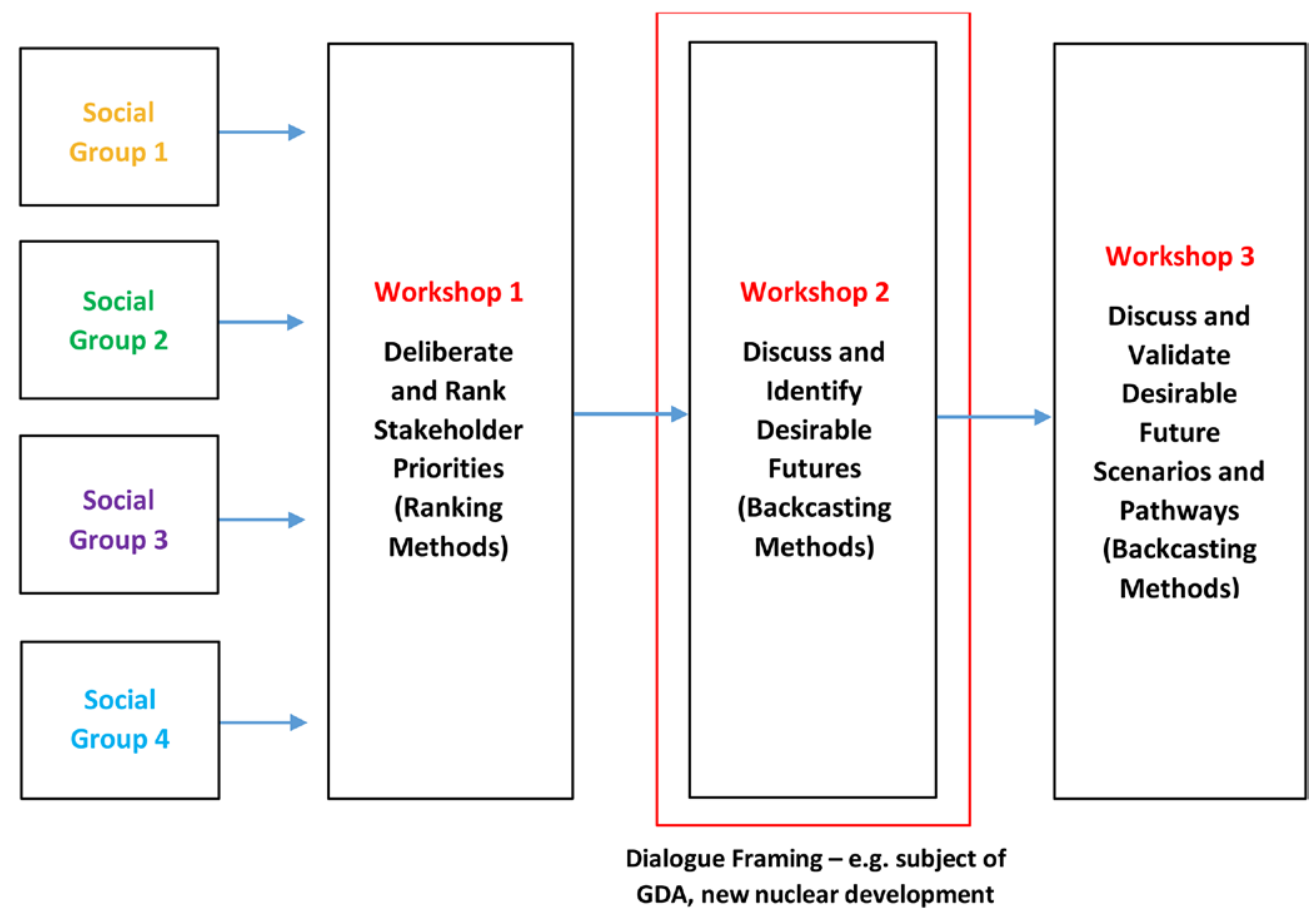

Figure 1. Conceptual framework for the prioritisation of engagement issues with various community-level social groups, and developing sustainable future pathways.

\section{Conclusions}

We have discussed previously that despite public engagement initiatives to discuss energy developments, there is currently an absence of process or appropriate dialogue to illicit a sustainable community response to the planned closure of several energy generation sites or the development of new energy infrastructure, such as nuclear energy and shale gas developments in the UK. We have reviewed the findings of a national scoping survey, carried out by consultants appointed by the Generic Design Assessment (GDA) Public Dialogue Pilot process convenors for new nuclear build in the UK. We have also reviewed the results of questions asked during the Round 1 and Round 2 workshops held as part of the process at 3 locations in the UK-Cheltenham, Bangor and Crewe. The findings from both the online scoping survey and workshop questions highlight persistent issues for engagement processes; these are:

- The disparity and conflict between 'national' engagement processes (such as GDA) and the specific requirements of those energy communities that live adjacent or close to energy infrastructure. In this process and others, we have seen an imbalance between the requirements of the convenor and those of participants regarding priority issues for discussion.

- Despite the preference for a remote, internet-based engagement process, participants agree that face-to-face contact (perhaps via existing social groups) is a priority to encourage trustbuilding between participants and the convenors of the process. In addition, those who live close to such sites should be encouraged to be involved in the engagement process by encouraging others to attend - more akin to an asset-based or capacity building approach. 
It is clear that the UK nuclear regulators have worked hard within current planning and consultation guidelines, often going further than what is required by law to encourage knowledge and trust-building. Issues of public interest and priority were highlighted by participants, but were unable to be engaged with fully due to these issues not being included within the scope of the process. The GDA Public Dialogue Pilot process has demonstrated that stakeholder are willing to be much more directly involved in the decisions that affect them, particularly at a local scale close to energy infrastructure sites. This tension continues to be a persistent challenge for those convening stakeholder engagement events-however, it is encouraging that convenors and participants alike continue to be willing to work towards resolving this.

To contribute to this debate, we have proposed a systemic, community-led, asset-based approach to societal dialogue [2]; one that captures the views and concerns of the wider stakeholder community and is able to inform views/decision-making at the community level and inform strategic levels of decision-making. As part of this asset-based approach, we recommend that the role of capacity building be implemented more greatly for nuclear energy projects, but also more broadly for nuclear legacy projects also. Indeed, if implemented for nuclear energy projects during construction and operation, this should be continued into decommissioning phases. Our conceptual framework allows us to derive a systemic view of community-led priorities - that is, the social construction of affected communities. We recommend that during future processes such as GDA Public Dialogue, which are inherently broad in their scope, that there be further utilisation of engagement with local stakeholders and greater identification of local stakeholder priorities. As a result, the plural impacts on affected communities, importantly from a community perspective, can be understood, and we recommend that this be achieved through more strategic engagement, i.e. multi-directional dialogue with different social groups. This type of process allow us to work towards a fair and equitable process when engaging with communities. Such recommendations align with recent industrial recommendations (e.g. [11, 14]), and despite the existence of practical challenges to their implementation, such as resource restraints and the possibility of inter-group differences, as we have highlighted, such recommendations are made in order to contribute towards resolutions and progress.

\section{References}

[1] Webler T, Tuler S and Kreuger R 2001 What is a good public participation process? Five perspectives from the public Environ. Manage. 27 435-50

[2] Whitton J, Parry I M, Akiyoshi M and Lawless W 2015 Conceptualizing a social sustainability framework for energy infrastructure decisions Energy Res. Soc. Sci. 8 127-38

[3] Rowe G and Frewer L J 2000 Public participation methods: a framework for evaluation Sci Technol. Human Values 25 3-29

[4] Brooks H and Johnson R B 1991 Comments: public policy issues The Genetic Revolution: Scientific Prospects and Public Perceptions ed B Davies (Baltimore, MD: Johns Hopkins University Press); pp 266-82

[5] Earle T C and Cvetkovich G T 1995 Social Trust (Westport, CT: Praeger)

[6] Slovic P, Fischhoff B and Lichtenstein S 1982 Facts versus fears: understanding perceived risk Judgment Under Uncertainty: Heuristics and Biases ed D Kahneman et al (Cambridge: Cambridge University Press) pp 463-90

[7] European Commission 2011 Directive 2011/92/EU of the European parliament and of the council of 13 December 2011 on the assessment of the effects of certain public and private projects on the environment Official J. Eur. Union L26 1-21 (http://eur-lex.europa.eu/LexUriServ/LexUriServ. do?uri=OJ:L:2012:026:0001:0021:En:PDF)

[8] Dunster H J and Mclean A S 1970 The use of risk estimates in setting and using basic radiation protection standards Health Phys. 19121 
[9] NRPB 1980 The Application of Cost Benefit Analysis to the Radiological Protection of the Public (A Consultation Document) (National Radiological Protection Board) (London: HMSO)

[10] Hill M D, Penfold J, Harris M, Bromhead J, Collier D, Mallet H and Smith G 2002 SAFEGROUNDS. Good Practice Guidance for the Management of Contaminated Land on Nuclear and Defence Sites. W13, CIRIA (London: Construction Industry Research and Information Association) (www. safegrounds.com)

[11] Towler P, Rankine A, Kruse P, Hill M, Penfold J, Smith G, Walke R, Egan M, Eslava-Gomez A and Collier D 2009 SAFEGROUNDS Good Practice Guidance for the Management of Contaminated Land on Nuclear-Licensed and Defence Sites version 2. W29, CIRIA (London: Construction Industry Research and Information Association) (www.safegrounds.com/pdfs/w29_safegrounds_ lmg_version_2.pdf)

[12] Stilgoe J 2009 The Road Ahead: Public Dialogue on Science and Technology (London: Sciencewise) (www.sciencewise-erc.org.uk/cms/assets/Uploads/Publications/SWcollectionHIGH-RES.pdf)

[13] Richardson P, Rickwood K and Rickwood P 2013 Public involvement as a tool to enhance nuclear safety Energy Strategy Rev. $1266-71$

[14] NIC 2014 In the Public Eye: Nuclear Energy and Society issue 1 (London: Nuclear Industry Council) (www.gov.uk/government/uploads/system/uploads/attachment_data/file/360669/In_the_ Public_Eye_-_Nuclear_Energy_and_Society_-_NICJuly2014.pdf)

[15] Whitton J 2010 Participant perceptions on the nature of stakeholder dialogue carried out by the nuclear decommissioning authority (NDA) PhD Thesis University Of Manchester

[16] Whitton J 2011 Emergent themes in nuclear decommissioning dialogue: a systems perspective Systems 33 132-49

[17] Dryzek J S 2000 Deliberative Democracy and Beyond: Liberals, Critics, Contestations (Oxford: Oxford University Press)

[18] Bond A, Palerm J and Haigh P 2004 Public participation in EIA of nuclear power plant decommissioning projects: a case study analysis Environ. Impact Assess. Rev. 24 617-41

[19] Cotton M and Devine-Wright P 2012 Making electricity networks 'visible': industry actor representations of 'publics' and public engagement in infrastructure planning Pub. Underst. Sci. 21 17-35

[20] Kemp R V, Bennett D G and White M J 2006 Recent trends and developments in dialogue on radioactive waste management: experience from the UK Environ. Int. 32 1021-32

[21] Cuppen E, Breukers S, Hisschemöller M and Bergsma E 2010 Q methodology to select participants for a stakeholder dialogue on energy options from biomass in the Netherlands Ecol. Econ. 69 579-91

[22] Bell D, Gray T and Haggett C 2005 Policy, participation and the 'social gap' in wind farm siting decisions Environ. Politics 14 460-77

[23] Devine-Wright P 2011 Renewable Energy and the Public: from NIMBY to Participation (London: Earthscan)

[24] Cabinet Office 2009 A summary of opinion poll about nuclear power ('Genshiryoku ni kansuru tokubetsu seron chousa no gaiyou.') Cabinet Office, The Government of Japan (http://www8.cao. go.jp/survey/tokubetu/h21/h21-genshi.pdf)

[25] ICRP 2015 First Announcement-International Workshop on the Fukushima Dialogue Initiative: 'Rehabilitation of Living Conditions After the Nuclear Accident' (Fukushima, Japan, 12-13 December 2015) International Commission on Radiological Protection (www.icrp.org/docs/First\%20 Announcement\%20International\%20Workshop\%2020150603.pdf)

[26] Aas Ø, Devine-Wright P, Tangeland T, Batel S and Ruud A 2014 Public beliefs about high-voltage powerlines in Norway, Sweden and the United Kingdom: a comparative survey Energy Res. Soc. Sci. $230-7$

[27] Walker G 1995 Renewable energy and the public Land Use Policy 12 49-59

[28] Wustenhagen R, Wolsink M and Burer M J 2007 Social acceptance of renewable energy innovation: an introduction to the concept Energy Policy 35 2683-91

[29] Burningham K 2000 Using the language of NIMBY: a topic for research, not an activity for researchers Local Environ. Int. J. Justice Sustainability 5 55-67

[30] Devine-Wright P 2009 Rethinking NIMBYism: the role of place attachment and place identity in explaining place-protective action J. Commun. Appl. Soc. Psychol. 19 426-41

[31] Batel S and Devine-Wright P 2015 A critical and empirical analysis of the national-local 'gap' in public responses to large-scale energy infrastructures J. Environ. Plan. Manage. 58 1076-95

[32] Funtowicz S O and Ravetz J R 1993 Science for the post-normal age Futures 25 739-55 
[33] De Marchia B and Ravetz J R 1999 Risk management and governance: a post-normal science approach Futures 31 743-57

[34] Ravetz J R 2004 The post-normal science of precaution Futures 36 347-57

[35] Ravetz J R 2006 Post-normal science and the complexity of transitions towards sustainability Ecol. Complexity 3 275-84

[36] Buhr K and Wibeck V 2014 Communication approaches for carbon capture and storage: underlying assumptions of limited versus extensive public engagement Energy Res. Soc. Sci. 3 5-12

[37] Irvin R and Stansbury J 2004 Citizen participation in decision making: is it worth the effort? Public Adm. Rev. 64 55-65

[38] European Commission 2003 Directive 2003/35/EC of the European Parliament and of the Council of 26 May 2003 providing for Public Participation in respect of the drawing up of Certain Plans and Programmes relating to the Environment and amending with regard to Public Participation and Access to Justice Council Directives 85/337/EEC and 96/61/EC Official J. Eur. Union L156 17-24 (http:// eur-lex.europa.eu/resource.html?uri=cellar:4a80a6c9-cdb3-4e27-a721-d5df1a0535bc.0004.02/ DOC_1\&format $=$ PDF)

[39] United Nations (UN) 1998 Aarhus Convention on Access to Information, Public Participation in Decision-making and Access to Justice in Environmental Matters (Aarhus: United Nations)

[40] Hartley N and Wood C 2005 Public participation in environmental impact assessmentimplementing the Aarhus convention Environ. Impact Assess. Rev. 25 319-40 (http://ac.els-cdn. com/S019592550400160X/1-s2.0-S019592550400160X-main.pdf?_tid=d558d82c-e203-11e59075-00000aab0f6b\&acdnat =1457094359_74953b734d10ff952c74106323c90d96) (Accessed: 5 March 2016)

[41] Cabinet Office 2012 Consultation Principles Crown Copyright; 17th July 2012 (updated 5th November 2013) (www.gov.uk/government/publications/consultation-principles-guidance)

[42] Warburton D 2012 Evaluation of the Environment Agency's Consultation on the Generic Design Assessment (GDA) for new nuclear power stations-Final Report (Brighton: Shared Practice) (www.sharedpractice.org.uk/Downloads/EA_GDA_evaluation.pdf)

[43] 3KQ 2015 New nuclear power stations: improving public involvement in Reactor Design Assessments 3KQ (Three Key Questions) Dialogue Report August 2015 (http://www.sciencewiseerc.org.uk/cms/assets/Uploads/GDA-dialogue-report-August-2015-FINAL.pdf)

[44] Innes J E and Booher D E 2004 Reframing public participation: strategies for the 21st century Plan. Theory Pract. 5 419-36

[45] Elam M and Sundqvist G 2007 Six domains of decision for stakeholder involvement in nuclear waste management CARL Thematic Report No. 4. December 2007 (www.karnavfallsradet.se/sites/ default/files/dokument/seminarier/302.pdf)

[46] Flueler T 2001 Option in radioactive waste management revisited: a proposed framework for robust decision making Risk Anal. 21 787-99

[47] Kos D, Polic M and Železnik N 2008 The framing of radioactive waste: a comparative analysis CARL Thematic Report No. 1. April 2008 (www.karnavfallsradet.se/sites/default/files/dokument/ seminarier/299.pdf)

[48] Devine-Wright P, Devine-Wright H, Sherry-Brennan F 2010 Visible technologies, invisible organisations: an empirical study of public beliefs about electricity supply networks Energy Policy 38 4127-34

[49] Krütli P, Stauffacher M, Flüeler T and Scholz R W 2010 Functional-dynamic public participation in technological decision-making: site selection processes of nuclear waste repositories J. Risk Res. 13 861-75

[50] Cotton M and Devine-Wright P 2012 Putting pylons into place: a UK case study of public perspectives on the impacts of high voltage overhead transmission lines J. Environ. Plan. Manage. 56 1225-45

[51] Cowell R, Bristow G and Munday M 2011 Acceptance, acceptability and environmental justice: the role of community benefits in wind energy development J. Environ. Plan. Manage. 54 539-57

[52] Rojanamon R, Chaisomphob T and Bureekul T 2012 Public participation in development of small infrastructure projects Sustainable Dev. 20 320-34

[53] Shamsuzzoha A H M, Grant A and Clarke J 2012 Implementation of renewable energy in Scottish rural area: a social study Renew. Sustainable Energy Rev. 16 185-91

[54] Lidskog R and Sundqvist G 2004 On the right track? Technology, geology and society in Swedish nuclear waste management J. Risk Res. 7 251-68 
[55] Dawson J I and Darst R G 2006 Meeting the challenge of permanent nuclear waste disposal in an expanding europe: transparency, trust and democracy Environ. Politics 15 610-27

[56] WCMRWS (West Cumbria Managing Radioactive Waste Safely Partnership) 2012 The Final Report of the West Cumbria Managing Radioactive Waste Safely Partnership (Copeland: Copeland Borough Council) (www.westcumbriamrws.org.uk/images/final-report.pdf) (Accessed: 12 February 2013)

[57] Collins K and Ison R 2006 Dare we jump off Arnstein's ladder? Social learning as a new policy paradigm Proc. of PATH (Participatory Approaches in Science \& Technology) Conf. (Edinburgh, 4-7 June 2006) (http://oro.open.ac.uk/8589/)

[58] European Union (EU) 2000 Directive 2000/60/EC of the European Parliament and of the Council (of 23 October 2000) establishing a framework for Community action in the field of water policy Off. J. Eur. Comm. L327 1-73 (http://eur-lex.europa.eu/legal-content/EN/ TXT/?uri=CELEX:32000L0060)

[59] Lee M and Abbot C 2003 The usual suspects? Public participation under the Aarhus convention Mod. Law Rev. 66 80-108

[60] Keen R 2015 Membership of UK Political Parties Briefing Paper (No. SN05125, 11 August 2015) House of Commons Library (http://researchbriefings.files.parliament.uk/documents/SN05125/ SN05125.pdf)

[61] MIDARP 2015 Marshall Islands Dose Assessment and Radioecology Program (website) (https:// marshallislands.llnl.gov/introduction.php)

[62] Miller C A, Richter J and O'Leary J 2015 Socio-energy systems design: a policy framework for energy transitions Energy Res. Soc. Sci. $629-40$

[63] Reed M S 2008 Stakeholder participation for environmental management: a literature review Biol. Conserv. 141 2417-31

[64] Walker B J A, Wiersma B and Bailey E 2014 Community benefits, framing and the social acceptance of offshore wind farms: an experimental study in England Energy Res. Soc. Sci. 3 46-54

[65] Magis K and Shinn C 2009 Emergent themes of social sustainability Understanding the Social Aspect of Sustainability ed J Dillard et al (New York: Routledge) pp 15-44

[66] Whitton J 2009 Stakeholder participation for the legacy ponds and legacy silos (LP\&LS) facility at sellafield, Cumbria, UK: the nature and effectiveness of the dialogue Proc. of ICEM 09 (Liverpool, UK, 11-15 October 2009)

[67] Beierle T C 2002 The quality of stakeholder-based decisions Risk Anal. 22 739-49

[68] Lawless W F, Akiyoshi M, Angjellari-Dajci F and Whitton J 2014 Public consent for the geological disposal of highly radioactive nuclear wastes and spent nuclear fuel Int. J. Environ. Stud. 71 41-62

[69] Pidgeon N 2011 Memorandum on Public Attitudes and Nuclear Power House of Lords Science and Technology Committee Inquiry on 'Nuclear R\&D Capabilities' (http://www.ukerc.ac.uk/ publications/memorandum-on-public-attitudes-and-nuclear-power-to-the-house-of-lords-scienceand-technology-committee-inquiry-on-nuclear-r-d-capabilities-.html)

[70] Raven R P J M, Jolivet E, Mourik R M and Feenstra Y C F J 2009 ESTEEM: managing societal acceptance in new energy projects. A toolbox method for project managers Technol. Forecast. Soc. Change 76 963-77

[71] Raven R P J M, Mourik R M, Feenstra Y C F J and Heiskanen E 2009 Modulating societal acceptance in new energy projects: towards a toolkit methodology for project managers Energy $34564-74$

[72] Cotton M 2014 Ethics and Technology Assessment: a Participatory Approach (Berlin: Springer) 